\title{
A Model for Understanding and Changing the Practice of Leadership in Ukraine
}

http://doi.org/10.21272/bel.5(4).17-31.2021

Michael Linville, ORCID: https://orcid.org/0000-0001-8820-2288

Ed.D., Associate Professor, Indiana Wesleyan University, Marion, Indiana, U.S.

Artem Kliuchnikov, ORCID: https://orcid.org/0000-0003-3989-6142

$\mathrm{PhD}$, Director, Analytical Center for Leadership Research and Development, Kyiv, Ukraine

\begin{abstract}
The practice of leadership dates to humankind's earliest history. However, the study of leadership is a much more recent phenomenon. Leadership is understood and practiced differently from culture to culture, though much academic research has been rooted in Western thought. Leadership exists in every facet of our lives because the societies around us significantly shape our very existence. Groups of people exist because, for most tasks and functions, groups can outcompete individuals. The very nature of groups is that they function best with one or more who serve as leaders while others serve as followers. As a result, the study of leadership facilitates a better understanding of the interpersonal dynamics between leaders and followers. In its simplest form, leadership may be understood as one individual influencing another, especially to work together to accomplish some common goal. The Analytical Center for Leadership Research and Development (ACLRD) has devoted the past several years to studying leadership theory and practice in Ukraine. This white paper summarizes that research, its purpose, methodology, and findings in providing the reader with analysis and insights into how leadership in Ukraine is perceived and practiced. In addition, this white paper proposes specific recommendations and the implementation of a research-based ACLRD Leader Model distinctly unique to Ukrainian culture and practices. Ultimately, this paper serves as a call for changes in the practice of leadership that hold great potential for benefiting Ukrainian organizations of all kinds as well as society at large.
\end{abstract}

Keywords: Leader, Leadership, Character, Virtues, Responsibility, Vision, Purpose, Empathy.

JEL Classification: M12, M14.

Cite as: Linville, M., Kliuchnikov, A. (2021). A Model for Understanding and Changing the Practice of Leadership in Ukraine. Business Ethics and Leadership, 5(4), 17-31. http://doi.org/10.21272/bel.5(4).17-31.2021.

Received: 27 October $2021 \quad$ Accepted: 28 November 2021

Published: 30 December 2021

Copyright: (C) 2021 by the author. Licensee Sumy State University, Ukraine. This article is an open access article distributed under the terms and conditions of the Creative Commons Attribution (CC BY) license (https://creativecommons.org/licenses/by/4.0/).

\section{Introduction}

Aristotle once wrote: "Man is by nature a social animal; an individual who is unsocial naturally and not accidentally is either beneath our notice or more than human. Society is something that precedes the individual" (Aristotle, 1981). Our very existence, therefore, is significantly shaped by the society around each of us. Human beings depend upon other human beings, mainly because different people possess different skills and abilities. If each person were equally skilled and talented in virtually every aspect of life, there would be little reason to depend on other people since we would have the ability to be self-sufficient. That is not how humanity works, however. People join in groups that offer different and complementary strengths to accomplish more than anyone could achieve. Groups of people exist because, for many types of tasks and functions, groups can outcompete individuals. It is the very nature of society.

Our connections to others are essential not only to our survival but also to our happiness and the success of our careers (Ember \& Ember, 2014). Out of this interdependence between individuals arises the dynamic of leadership. The notion of leadership can be viewed as a bit of a mystery because it brings together the best and worst in human nature: love and hate, hope and fear, trust and deceit, service, and selfishness. Leadership draws upon who we are but also shapes what we might become. As self-regarding creatures, how we see ourselves often influences our satisfaction in our relationships with others (Jhangiani \& Tarry, 2015). And our 
ability as humans to reflect, using both reason and emotion, allows us to learn from our mistakes, though our selfish nature interferes with the effectiveness of our reflections (Brooks, 2012).

What is Leadership. A close examination of the phenomenon of leadership forces us to tackle specific universal questions about human nature. We study leadership better to understand the interpersonal dynamics between leaders and followers. To begin with, though, it helps define what is meant by the term "leadership". In its simplest form, leadership may be understood as one individual influencing another, especially to work together to accomplish some common goal (Kouzes \& Posner, 2008). A more extensive definition of leadership is more comprehensive: Leadership is the capacity to create and communicate vision across various organizational contexts that both serve and transform followers to embrace actionable change in ways that produce mutually desirable outcomes. How this is practiced, however, does vary from culture to culture. Best practices in leadership in the West may or may not represent best practices in leadership across Ukrainian society. Until now, ACLRD is unaware of any study that has comprehensively considered how leadership is perceived and practiced in Ukraine.

The Duality of Human Nature. Ultimately, however, we must consider our divided double nature, being both social and self-regarding, because it typically exacerbates the divide between group and individual. We want to gain autonomy and independence; at the same time, however, we want to share our lives with others and to rely on others. It is precisely that need for reliance on others that necessitates the role of a leader. Working collectively in groups is more efficient when members help keep others focused on a shared vision of expected goals (Miller, 1993). As we explore the phenomenon of leadership in this white paper, we do so by asking and, at times answering, certain difficult questions. For example, a leader's job description is inherently utilitarian. However, an objection to this idea arose when some scholars asserted that most leaders cannot or do not know the greatest good for the most significant number of people. Moreover, leadership can be considered a constant power transaction. The power that sustains leadership over time is that power which followers are willing to give leaders.

There are many good reasons to want strong leaders, but there are just as many reasons to fear them. We may need leaders for order and control, but we will always face the problem of controlling the controllers. One may see examples of this the world over. Ukraine certainly has seen its share. Leaders should be held to the same moral standards as others because morality negotiates the distribution of power. For example, leaders who trust and trust their followers typically possess more power yet conversely need less power to lead. And we must be aware that the psychological aspects of leadership involve a dark side/bright side dichotomy: the dark side is manipulation; the bright side enables leaders to help groups lead themselves. Ultimately, we need leaders to give us order and security so that we can be free to pursue our wants and needs (Lipman-Blumen, 2006). The alternatives frequently are dysfunctional societies that eventually devolve into failed states.

The Role of Virtuous Ethics. Morality and ethics play a critically important role in the way leaders create environments of security and order within organizations. Leaders may articulate commonly held moral beliefs, yet the display of leader actions and behaviors may contradict what those leaders say they believe is moral. Who among us has not observed this in leaders at one time or another? For example, both totalitarian and democratic systems claim to provide order and security. Yet stark differences exist between them. The delineating factor is the system of values or ethical principles. There are many approaches to determining an ethical framework. The Analytical Center for Leadership Research and Development subscribes to and espouses one of the significant normative approaches to ethics - virtue ethics. This framework emphasizes an individual's moral character rather than focusing on the outcomes of one's actions (utilitarianism) or rules and duties (deontology). Virtue ethics is concerned with practical wisdom, which is based on the individual leader's set of values (Schwartz \& Sharpe, 2006).

The Language of Leadership in Ukraine. In the years after Ukraine's 2014 Revolution of Dignity, leadership has become a "buzz word." Google's Trends service registered a spike in the use of leadership as a key search word (in both Russian-speaking and Ukrainian-speaking segments of Internet users in Ukraine). The leadership construct has become part of the discourse in Ukraine, which spilled into the emergence of leading schools in the country: the Ukrainian Leadership Academy (ULA) and the Leadership Academy for Development at Ukraine Catholic University, to name a few. However, there is an apparent crisis of leadership in the country. The situation is aggravated by the economic, political, and legal context in which the leaders in Ukraine must function. As Ukraine strives toward becoming part of the EU, it is important to understand what leadership practices make Western countries successful. However, to change, one must first understand the current state of affairs and the context in which leadership is practiced in Ukraine. 
The Research Speaks: What is a Leader in Ukraine? Transferring Western leadership concepts into Ukrainian contexts and realities, frankly, may well be characterized as having been "lost in translation". The situation, however, is aggravated by the economic, political, and legal contexts in which leaders in Ukraine must function. An examination into the construct of leadership as practitioners perceive it in Ukraine and an overview of the differences between Ukrainian and Western perceptions of the word has been conducted through ACLRD's seminal research in recent years. ACLRD research reveals essential insights into the theoretical basis for leadership in Ukraine and how it is perceived and practiced. This research also justifies continued work in this important area as these findings hold significant implications across all institutions of Ukrainian society.

Leadership Theories. There have been no completed studies that focused exclusively on effective leadership attributes or theories in Ukraine. Leadership theories originated largely in Western contexts and, until recent years, with little regard for their universality across other cultures. However, the assumption of universal relevance of leadership theories have been challenged on numerous occasions (Fairhurst \& Grant, 2010; Holt, Bjorklund, \& Green, 2009.) Lord, Brown, et al. (2001) posited that no single leadership theory or model can be applied across all cultural contexts, because "leadership is co-constructed, a product of sociohistorical and collective meaning making, and negotiated on an ongoing basis through a complex interplay among leadership actors, be they designated or emergent leaders, managers, and/or followers" (Fairhurst \& Grant, 2010: 172). In determining how relevant leadership theory may inform leadership practices in Ukraine, it is essential to note that the phenomenon of leadership may be understood as one or more of three different applications. These include (1) a formal position occupied by the leader, (2) personal characteristics of a leader, and (3) the behaviors of a leader (Fey, Adeava \& Vitkovskaia, 2001).

Research in non-Western cultures has suggested that leadership practices within any society may evolve as the society itself changes (House et al., 2014; Offermann \& Coats, 2018), meaning that understanding leadership theory and praxis may occur in a regular state of flux. While Ukraine is not Russia, recent research argues that the traditional "control-oriented" approach to leadership in Russia is slowly transitioning to leadership more typical of Western culture (McCarthy, Puffer, \& Darda, 2010). No such research exists in Ukraine, so any such assertion this would be the case in Ukraine is without support. We are left with the need to understand better the relationships between leadership theories and practices within Ukrainian society. Four leadership theories merit further consideration in investigating leadership practices as likely they have evolved or are evolving in Ukraine, as well as many CIS countries: autocratic leadership, paternalistic leadership, transactional leadership, and transformational leadership.

Autocratic Leadership. Organizations that experience autocratic leadership tend to be "ruled" by strong leaders who expect the subservience of employees beneath them. Such executives typically value hierarchy and formal status. They commonly expect to receive privileges and recognition, often avoiding interaction between themselves physically from lower employees. Such leaders demand loyalty and do not usually seek employee feedback (Kets de Vries, 2000).

Paternalistic Leadership. Farh and Cheng (2000) defined paternalistic leadership as "combined strong discipline and authority with fatherly benevolence and moral integrity" (p. 84). Typically, paternalistic leadership is comprised of authoritarianism, benevolence, and moral leadership (Cheng et al., 2004). It stands in contrast to autocratic leadership largely in that paternalistic leadership includes the benevolence characteristic, implying that such leaders care for subordinates and have an interest in maintaining a personal relationship with them (Ünler \& Kılıç, 2019).

Transactional Leadership. Leaders who follow a transactional leadership approach tend to be inflexible and focused on policies, procedures, and rules. Transaction leaders may be said to operate in a "quid pro quo" manner, simply meaning that they do something for someone in exchange for that individual doing something for them. An English colloquialism characterizes this theory well: "you scratch my back and I will scratch yours". While transactional leadership tends not to be valued by leadership, thought leaders in the West, the lack of trust that often exists in societies that have experienced autocratic leadership may discover that transactional leadership affords a more dependable, if not trustworthy, relationship between leaders and followers. Thus, this theory may be viewed as making progress in fostering better leader and follower dynamics.

Transformational Leadership. Transformational leadership is defined as one person engaging with others in an inspirational way that builds a relationship, subsequently enhancing the motivation for both and promoting the common good (Kouzes \& Posner, 2002; Northouse, 2013). As such, researchers asserted that there is a 
moral component to transformational leadership. At its core, there is the concept of leaders being intentional in understanding and adjusting to the needs and motives of those who follow them (Northouse, 2013). Characteristics of a transformational leader include worthy role models, change agents, visionaries who possess the ability to articulate organizational goals, empower others, and evoke trust by followers (Northouse, 2013). The transformational leadership theory does not prescribe a particular set of leaders' actions or activities but rather provides a general framework that espouses innovation, inspiration, and ideals. Intuitively appealing, transformational leadership is notable for its emphasis on the needs and values of followers (Bennis \& Nanus, 1985; Northouse, 2013). Transformational leadership has been among the most popular leadership theories in Western leadership thought for the past 40+ years. The application of this theory in the Ukrainian context, however, remains untested.

\section{Purpose}

The Analytical Center for Leadership Research and Development advocates leader best practices as studied and analyzed in the West. However, at ACLRD, we also understand the importance and nuances of the local culture, and we are committed to contextualizing leadership practices in Ukraine. This tension is best represented by a comment shared by one businessman in Kyiv: "Why do you teach us - penguins - the ways of life in Africa?" He implied that the context and understanding of life are so significantly different between the West and Ukraine that theories and practices developed in Western culture are foreign and, even more so, irrelevant to Ukrainians. Was he correct when he said this? Yes. Was he wrong in his statement? Also, yes. Ukraine understandably struggles with a lack of sound and effective leadership, precipitated by a significant lack of understanding about the roles, forms, and functions that leadership requires.

Considering ways of leading that are practiced in first-world countries offers deep insights into needed changes in Ukrainian leadership practices. At the same time, these approaches must be critically assessed and creatively implemented to align with a given country's cultural mentality and context. In highlighting the perceptions of leadership as they exist in Ukraine, along with recommendations on how to change leadership practices for the better, the authors hope to provide valuable, data-driven insights for both indigenous leaders and expatriates who desire to contribute to the development of successful organizations and a prosperous Ukrainian economy. Ultimately, Ukrainian society stands to benefit from the emergence of high-quality leaders who have acquired the necessary skills and competencies to lead with excellence.

\section{Methodology}

A brief explanation of the methodology used to investigate how leadership is understood in Ukraine is appropriate. The researchers employed a phenomenological approach in exploring the social construction of leadership, a sort of "in the eyes of the beholder" approach. A series of interview questions were compiled and then published in Google Forms. Surveys were distributed through social media platforms. The resulting data prompted additional questions that were published on the Facebook page of The Analytical Center for Leadership Research and Development (ACLRD). Participants who submitted their responses were asked to respond to follow-up questions. Responses were inductively analyzed by applying qualitative research principles. Patterns and themes were derived from the data and the researchers did not follow any pre-existing framework. Recurring regularities in the data provided insights into the themes that represented understanding of leadership in Ukraine. No deviant cases were discovered that would not fit the dominant patterns observed in the responses. The total number of respondents in the initial study was 88 , of which $86.4 \%$ identified as female and $13.6 \%$ as male. The occupational background included schoolteachers, university students, medical workers, engineers, managers, government officials, entrepreneurs, and other workers. The population represented in the study ranged was aged 16 to 64 years. The most highly expressed group in the survey was aged 36 to 43 years.

\section{Research Findings}

The survey responses revealed a certain dichotomy in the perception of the term leadership. The concept of leadership evoked both highly positive and highly negative emotions. Those who held negative perceptions stated that they do not trust leaders and feel skeptical about the term itself. Some also mentioned that the concept has recently been abused and misused in Ukraine and that there is no true leadership in the country. However, the research surfaced responses representing the opposite opinion, as well. The proponents of leadership spoke about inspiration and positive attitudes that the term "leadership" evokes. The positive reactions included the desire to learn from leaders and feelings of admiration and pride. In follow-up conversations, some respondents mentioned that the delineating factor between admiration and skepticism is 
understanding the leadership construct. They suggested that many people still equate leadership only within the political arena and, therefore, it results in mostly negative perceptions of the concept. According to the respondents, other reasons for the observed dichotomy may be the proactive/reactive predisposition of everyone. In other words, if a person takes a more reactive stance, where a leader should take care of them, most likely it will evoke negative perceptions of leaders because they are not on par with their subordinates' expectations. However, more proactive segments of society may not hold such negative leadership views simply because they engage in leadership themselves. Another contributing factor to the negative perceptions of leadership in Ukraine is the corrupt system that permeates all societal spheres. Ukrainians tend to be more idealistic early in their career, thinking that they can bring about change, only to discover later they have become part of the system they previously disliked.

Data analysis showed the most prominent characteristic of a leader in Ukraine is responsibility. This construct was mentioned in responses to most questions in the surveys conducted. Responsibility was the most cited characteristic in four of eight questions and was the second most cited trait in two other questions. The respondents felt that a leader should carry the burden of responsibility for the organization as a whole and, in some instances, even be responsible for the decisions made by their subordinates. This prominent revelation prompted a follow-up question, "According to your responses, the most important characteristic of a leader is the ability to take responsibility. Why is it such an important leadership characteristic? Do leaders shun responsibility? Should subordinates take responsibility upon themselves as well?" The consensus among the responses was that responsibility differentiates a leader from kerivnyk (Ukrainian word for appointed leader). Some respondents went so far as to assert that a leader is a role model that exemplifies good moral and virtuous behavior.

Another prominent characteristic of the perceptions of the Ukrainian leader turned out to be confident. This characteristic created a strong combination with responsibility. In essence, this combination resembles some features of paternalistic leadership. One definition stated that paternalistic leadership is characterized by "restricting responsibilities of those subordinate" to leaders. While no respondent approached responsibility issues from the standpoint of "restricting" subordinates' responsibilities, it is noteworthy that the locus of control lies with the leader both in responsibility and confidence. Indeed, these are among the characteristics of a paternalistic leader. While these two attributes of leadership were mentioned throughout in answers to most of the questions, the results also revealed differences that respondents perceived between business, political, and non-profit leaders.

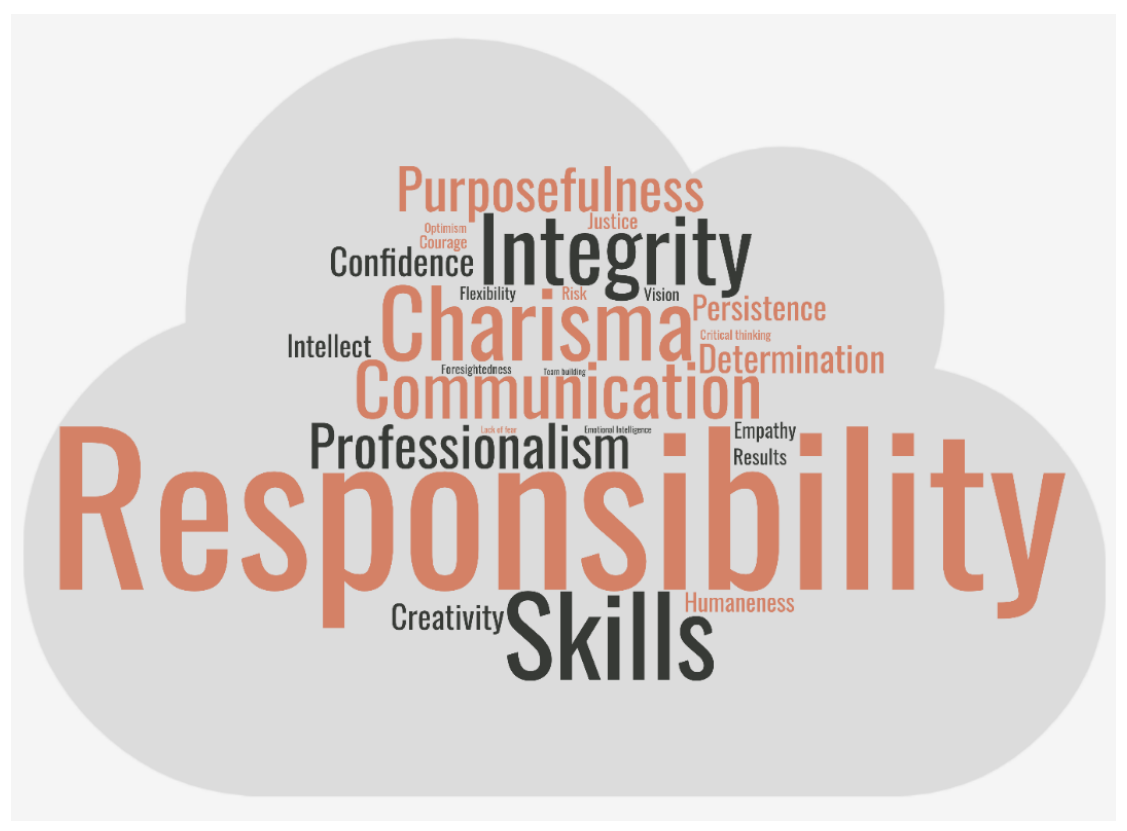

Figure 1. Word Cloud Depiction of Qualitative Data Results

Source: Compiled by the authors

Political Leadership. In political leadership, the most prominent characteristics were responsibility, integrity/honesty, and charisma. These three components were mentioned more than all other characteristics combined (Figure 2). It implies that the moral qualities of the leader become most important in the political arena (we can include justice into this category as well). However, responsibility continues to point to an external locus of control on the side of the followers. Intellect, skills, and professionalism show the importance 
of the abilities of a political leader. Communication implies transparency. In fact, communication failure on the part of Petro Poroshenko was cited as one of the reasons for his defeat in the presidential election of 2018, according to some political commentators (Дев'ять причин, чому програв Порошенко, і що йому робити далі, n.d.; (50 експертів оиінили роботу президента Порошенка за 12-бальною системою, 2018) (Nine reasons why Poroshenko lost and what he needs to do next, n.d.; 50 experts evaluated President Poroshenko's work on 12 point scale, 2018). Purposefulness and foresightedness may comprise strategic dimensions of political leadership, such as awareness of personal values, goals, and aspirations and the ability to expect future trends. Therefore, the four most important dimensions of political leaders were ethics/morality, hard skills, transparency and strategic thinking.

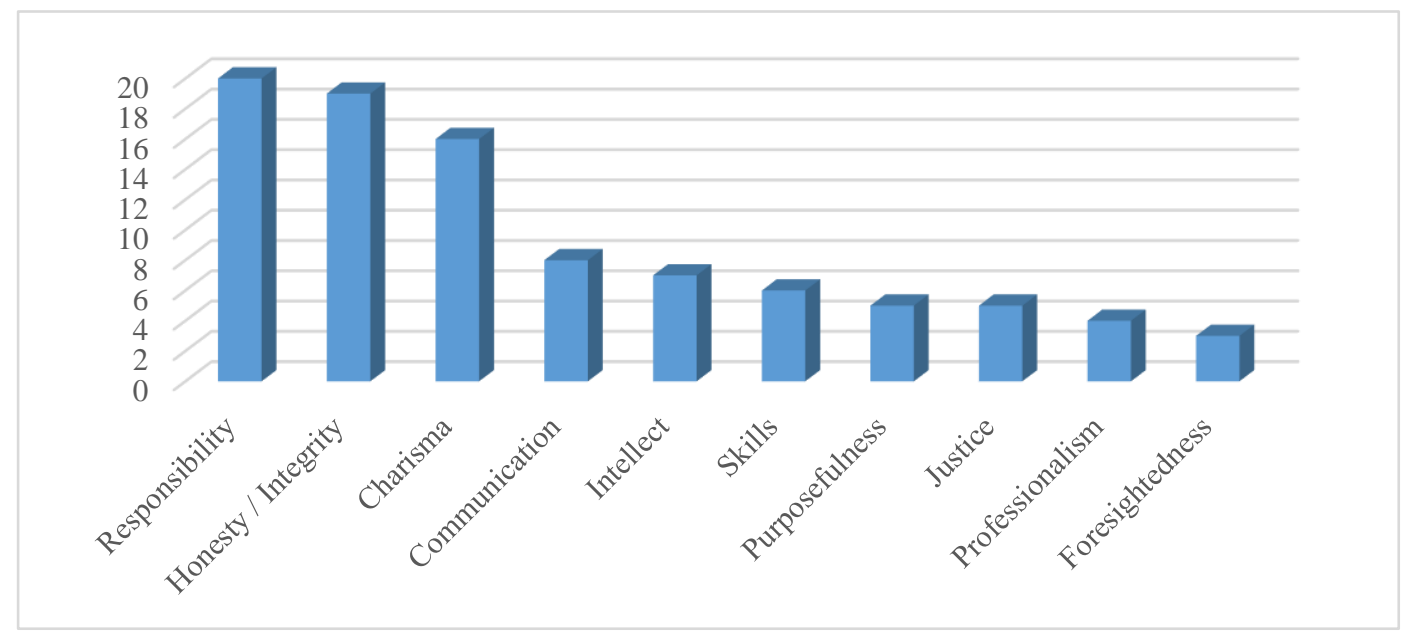

Figure 2. Characteristics of a Political Leader

Source: Compiled by the authors

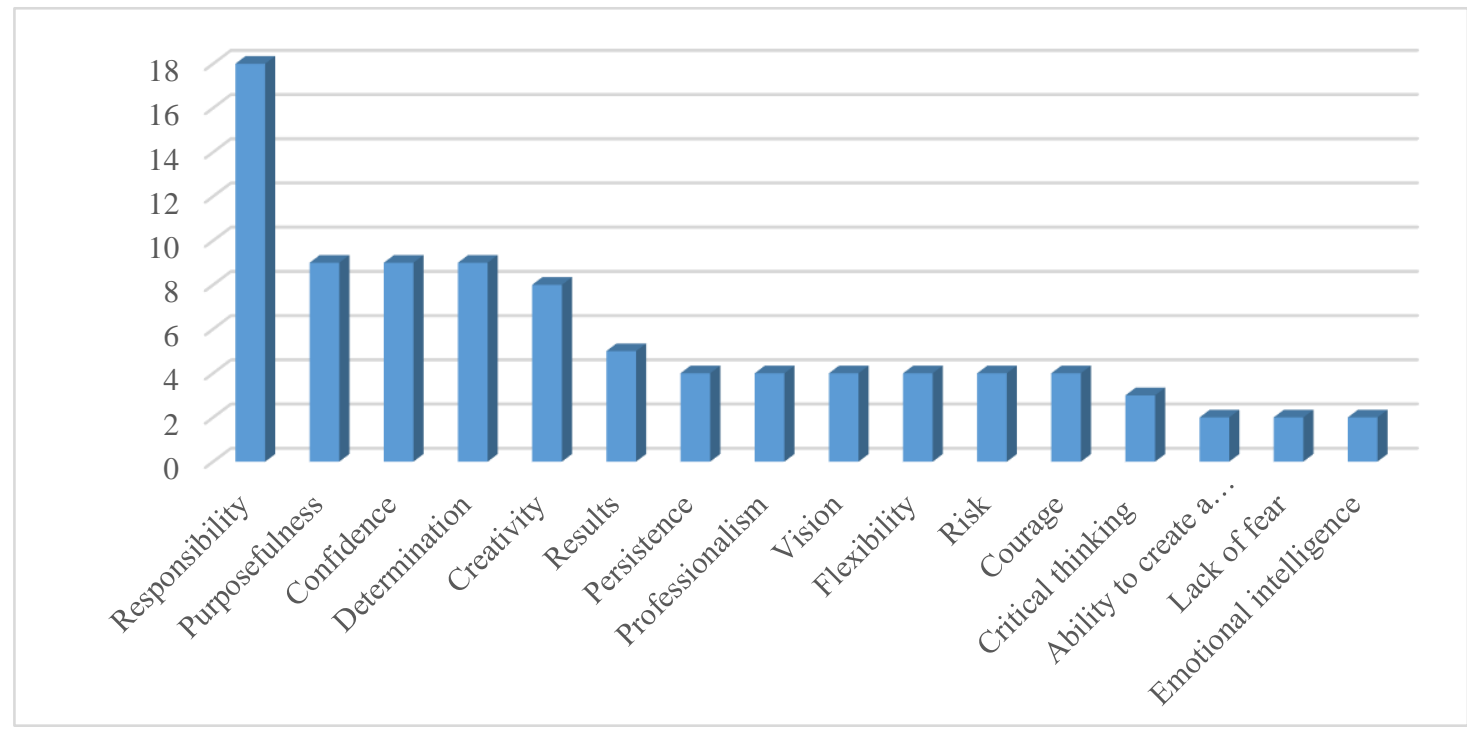

Figure 3. Characteristics of a Business Leader

Source: Compiled by the authors

Business Leadership. In business leadership, the palette of characteristics was broader than in political leadership, with responsibility being the most outstanding attribute of a business leader. This trait was mentioned twice as frequently as the second most cited characteristic, purposefulness (Figure 3). According to this study, purposefulness, confidence, and determination were three features considered important in equal measure. The analysis suggested that a business leader must be a self-sufficient and strong individual who is capable of charting a course into the future for his or her followers, combining them with vision, courage, risk taking, persistence, lack of exhibiting fear, and the addition of the paramount factor of responsibility. Creativity, flexibility, and critical thinking imply the leader's adaptability and ability to change. Professionalism and results point to the hard skills of a leader, his or her ability to deliver on promises, plans, and vision. Of particular interest is that soft skills like emotional intelligence placed last in the description of 
a business leader. The overall characterization of a business leader pointed to the dimensions of power, control, adaptability, hard skills, and the minor presence of soft skills.

Not-for-Profit Leadership. The not-for-profit sector represented the only leadership sphere where responsibility was not classified as the highest priority. Instead, skills were perceived as the essential trait among not-for-profit leaders (Figure 4). In the not-for-profit arena, respondents valued a relevant skillset that helps nonprofit organizations to function well within their specific focus areas. Skills, along with professionalism and competence, created a well-defined expectation for followers to see their leader as a true professional. Not-for-profit leadership was the only leadership sphere where soft skills gained traction. Empathy and humaneness were important in the not-for-profit context. Two other characteristics, optimism and charisma usually were viewed as subsets of charismatic leadership. For followers, these qualities are uplifting and motivational. In the nonprofit arena, where compensation and financial benefits do not necessarily correlate to the performance of an employee, the leader's intrinsic motivation becomes very important and that is apparent in this choice of leader characteristics.

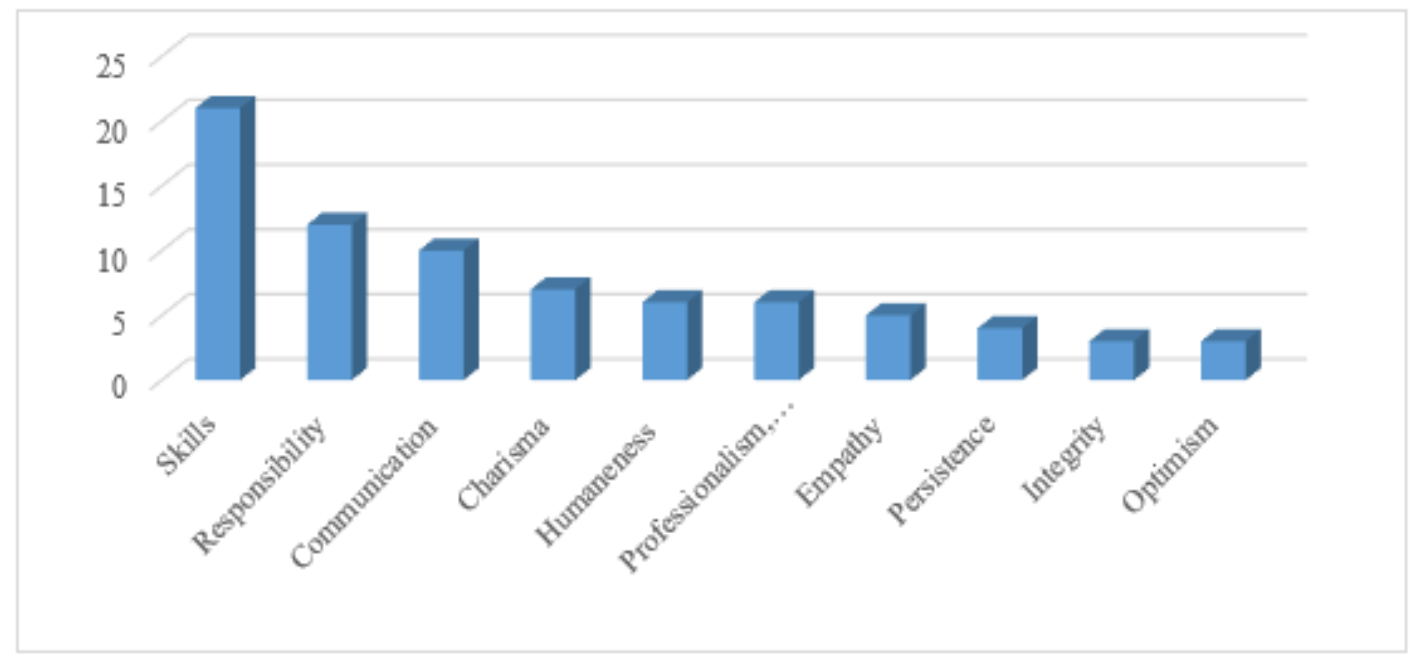

Figure 4. Characteristics of a Non-for-Profit Leader

Source: Compiled by the authors

\section{Analysis}

Respondents in the study provided their ideas about responsibility being a focal point of effective leadership. However, additional insights are to be gained from this study, stemming from cultural dynamics that exist in Ukraine. Comparisons were drawn between two other countries: the United States (largest economy in the world in 2019) and Germany (largest economy in Europe in 2019) to provide an in-depth understanding of existing practices. The comparison considered three characteristics unique to particular cultures developed by researcher Geert Hofstede.

Power Distance, Individualism, and Masculinity. Power Distance refers to the inequality that exists within a society. This dimension expresses the degree to which the less powerful members of a society accept and expect power to be distributed unequally. In high Power Distance cultures, employees tend to prefer autocratic/paternalistic leaders, whereas, in low Power Distance societies, employees express a preference for consultative/collaborative leaders (Hofstede, 2001). As Figure 5 shows, Power Distance is low in both Germany and the United States. Ukraine, in stark contrast, exhibits a very high Power Distance. This phenomenon of Power Distance should be considered together with the dimension of Individualism. The cultural dimension of Individualism focuses on the degree of interconnectedness between individuals in society. In high Individualistic cultures, the interpersonal relationships between individuals tend to be less tightly connected, and everyone is regarded based on their skills, achievements, and character. In low individualistic (or high collectivistic) societies, people are treated based on their group affiliations. Groups protect their own in exchange for unquestioning loyalty (Hofstede, 2001). In this study, Ukraine scored much lower on individualism, which suggests the cultural preference is collectivism. This conclusion aligns with previous cultural dimension analysis in Ukraine by other scholars. High power distance and high collectivism (low individualism) support the idea of responsibility as one of the primary characteristics of effective leadership in Ukraine. An examination of the leadership literature suggests that paternalistic leadership is considered a valued characteristic in collectivistic cultures. Moreover, in collectivistic cultures, more 
responsibility-taking for others is apparent (Kim et al., 2006). This dynamic between Paternalism and Collectivism is enforced by the idea of a strong, self-sufficient leader, and that perception is supported by the high-power distance cultural dimension.

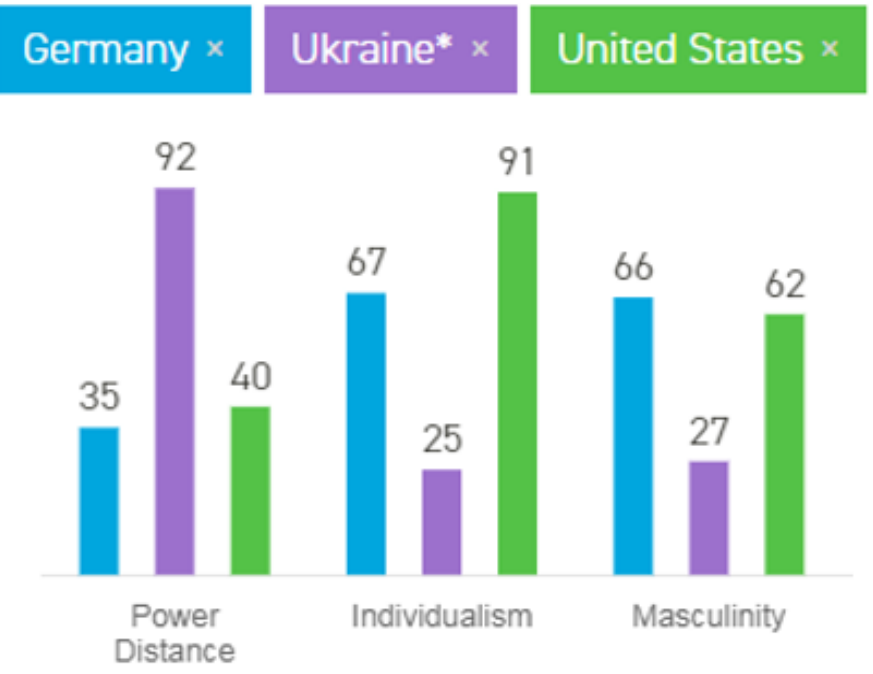

Figure 5. Cultural Dimensions by Hofstede

Source: Compiled by the authors

The cultural dimension of Masculinity addresses the level of assertiveness that exists in a given culture. A culture that scores high in Masculinity tends to be more firm, forceful, and assertive, whereas a culture that displays low Masculinity scores emphasizes relationships over tasks as well as emotional bonds (Hofstede, 2001). As the comparison chart shows, Ukraine scores low as a strong culture, especially in the United States and Germany. Therefore, while dominant behavior may be expected from the boss (a leader) due to high power distance, such behavior is not as appreciated when it is expressed among peers (followers). Moreover, this dimension points to the relational focus that typifies Ukrainian culture. The result is a culture with strong personal ties, where nepotism may flourish this combination of low masculinity with high collectivism. The authors conclude that this dynamic is readily apparent in Ukrainian society. A review of the most successful economies demonstrates that there are different factors at work regarding leadership. Therefore, with the goal of better understanding and improving leader-follower relationships and behaviors in Ukraine, we may gain insights by considering specific leadership practices within Western cultures.

Responsibility: Misunderstood and Misapplied. There seem to be as many views of leadership as there are people who practice or observe it. However, within this diversity, there are some commonalities in views. In Ukraine, ACLRD research suggests that the most common expectation of a leader is accepting responsibility. In many organizations, responsibility is a defining factor of the working relationships between leaders and non-leaders. Responsibility is closely connected with a Ukrainian leader's accountability and authority. As scholar McGregor (1960) posited in his seminal work, many Ukrainian leaders ascribe to "Theory X", a theory built on the assumption that workers are inherently lazy, and if the leader does not micromanage them, they will not work or produce. In other words, leaders tend to reduce their followers' feeling of responsibility by a command-and-control culture. This fuels employees' thinking about responsibility being a leader's primary characteristic. In actual practice, however, despite not allowing workers (followers) the freedom to bear responsibility, leaders still blame their followers for failures rather than owning up to themselves. Therefore, the fundamental lack of understanding in how responsibility has been applied, led to finger pointing between leaders and followers.

How Organizations in Ukraine Could Benefit from Learning Best Practices. The widely accepted concept of shared responsibility between stakeholders - toward the organization's mission, vision, and short-term goals - is a critically important factor in beginning to establish best practices. Shared responsibility, in fact, implies personal accountability. It means that everyone on the team (a) takes responsibility for one's own actions and their effects and (b) is open and willing to provide explanations and justifications for one's actions and decisions (Dubnick, 2003). While there are too many practical recommendations to be made that fit the scope of this white paper, The Analytical Center for Leadership Research and Development (ACLRD) offers additional key recommendations for leader and organizational effectiveness. (A more comprehensive report on the complete scope of recommendations will be forthcoming). 
Practical Recommendations. The average lifespan of an organization in the United States is 40 years (Goodburn, 2015). Unfortunately, such statistical data is not readily available in Ukraine. However, if we consider that Ukraine gained its independence in 1991, the oldest business venture in Ukraine maybe 29 years old. One may assume that maintaining business in this country may be a challenge, given that Ukraine suffers from corruption and an unstable economy. We often hear from Ukrainian business leaders that the future is so volatile that investing in it is a bad idea. It contributes to the short-term mentality prevalent in developing and executing a business. However, a solely short-term focus is detrimental to any organization as it strongly prefers current profits over innovativeness. Indeed, this is a necessary aspect for an organization. Finances drive business. Yet, innovation contributes to revenue in the long term, helping organizational sustainability. With this in mind, both short-term and long-term perspectives must be present in any organization. Focusing only on the here and now typically leads to failure at the first sign of internal or external difficulties. The mission of an organization and the vision for its future are not mere philosophical exercises but essential responsibilities that create competitive advantage and contribute to an enterprise's longevity. While a detailed discussion of the organizational vision and mission specifics is impossible within the format of this paper, the key principles that support these two ideas are the mission of an organization is why it exists (and the statement should be short enough to fit on a T-shirt in readable font size - example: Zoomko - We Build Cars); the vision for an organization is how it should look like ten years from now to best serve and support its mission (this becomes a more expanded description of how an organization should look to best fulfill its mission). The vision statement typically is not publicized but rather used primarily internally to keep stakeholders of the organization focused and headed in the right direction.

The ACLRD Leader Model. The Analytical Center for Leadership Research and Development (ACLRD) Leader Model begins with the leader since the leader serves as the organization's chief change agent and shapes new organizational best practices. ACLRD's collected research data provides insights into the qualifications of a leader capable of effectively leading an organization. As was noted earlier in the research findings, certain distinct characteristics exemplify each category of leaders: political, business, and nonprofit. Effective political leaders must have integrity, charisma, and a desire to communicate with their followers. Business leaders are confident, determined, and driven by purpose. They possess courage and take risks. Not-for-profit leaders are expected to be humane and to show empathy. One interesting question from the research analysis is whether a political leader would benefit from having a purpose and then being determined to stand for that purpose. Furthermore, what about being empathic in the process? Similarly, we may address the qualities of leaders in business and the non-profit arenas. Adding key characteristics of leaders in each domain, we strengthen leaders' capacities to lead. After the data analysis, we have chosen the most prominent features (temporarily setting aside the role of responsibility) that respondents highlighted for each leadership domain. Those characteristics then led to our creation of the following leadership model (Figure 6).

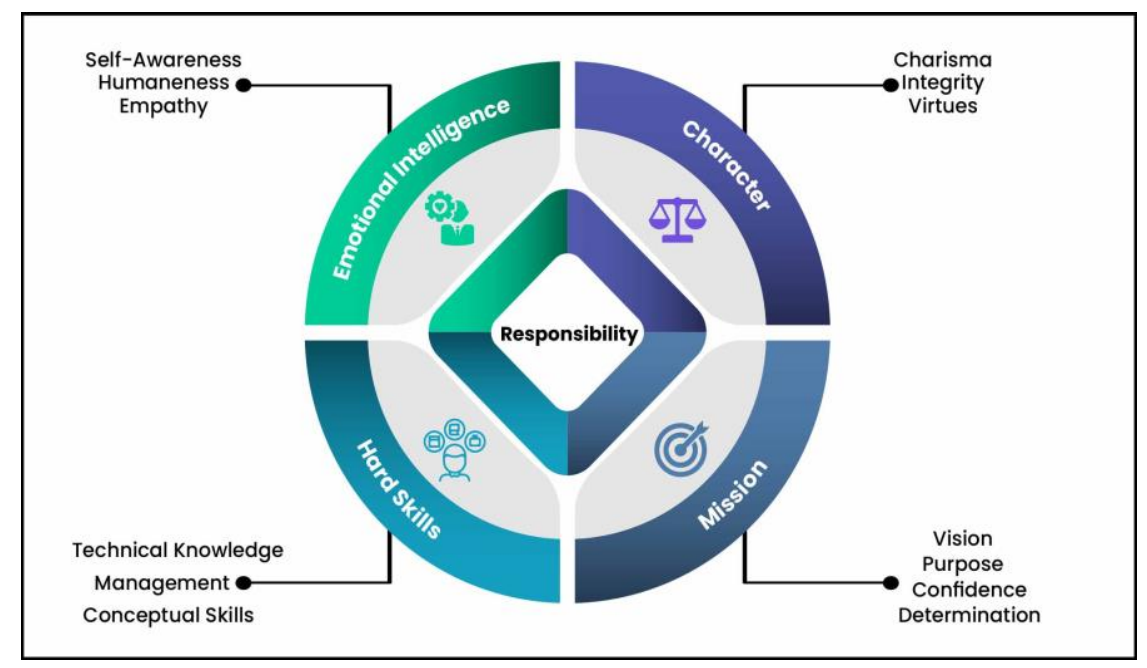

Figure 6. Leader Model

Source: Compiled by the authors

The characteristics are divided into four domains: character, mission, emotional intelligence, and hard skills.

The Character Quadrant. Leadership begins with self-leadership. In other words, leaders cannot effectively influence and create change in their organizations (and in the world) until they have tackled the often-difficult work of creating change within themselves. Character is not the most intuitive aspect, however, when it comes 
to leadership. Behavioral and clinical psychologists rejected the notion of character in the early twentieth century as a subjective phenomenon (Sarros et al., 2006). However, many newsworthy events of the past few decades (such as the Enron scandal) highlighted the importance of this aspect in leadership. As a result, social scientists, including those who study leadership, refocused on the character again (Tjeltveit, 2003). The question one may ask is: How does character help my organization (and me) survive? This subtle question may seem counterintuitive in a discussion of the business world, and it may seem impossible to quantify the impact of character on an organization. However, the highly influential KRW consulting agency conducted extensive research, discovering that

After 7 years, 100+ organizations, and more than 1 million data points, we now know Leadership Character Reputation is one of the strongest predictors of an organization's success. Senior teams with a strong character reputation average $\sim 5 x$ greater ROA, $+26 \%$ Employee engagement, and notably less risk than peers with a self-focused reputation (Our Thinking, 2020).

The character has been defined in many different ways. Perhaps the simplest way to understand the character is to represent the aggregate of traits forming one's nature, reputation, and moral or ethical qualities. The Character quadrant of the ACLRD Leader Model, as applied to Ukrainian culture based upon our research, incorporates three specific attributes of character, though character certainly involves many more qualities than just the three discussed herewith. The Greek philosopher Aristotle taught that one's character is formed by his or her actions (Aristotle, 1981). The habits, actions, and emotional responses in those of good character should lead to what is good and moral. When one considers the attributes of a leader, the character is an excellent place to start.

"The happiness of your life depends upon the quality of your thoughts: therefore, guard accordingly, and take care that you entertain no notions unsuitable to virtue and reasonable nature" (Aurelius \& Gill, 2013: 155). That admonition was uttered by the Roman Emperor Marcus Aurelius in the second century AD. By definition, virtues reflect one's moral excellence. A morally excellent individual possesses a character that is comprised of those virtues that society deems to be good. Virtues include qualities like kindness, courage, honesty, and respect, to name just a few. Virtuous people do not give in to impulses or inappropriate desires but rather very intentionally exercise self-control by doing the right things and displaying actions that align with good values and principles. Dr. Jay Wood, an accomplished philosophy professor, put it this way: Virtues are "abiding, reliable traits that allow us to orient our lives - our believing, perceiving, reasoning habits and so on - in ways that contribute to human flourishing" (Wood, 1998: 47).

There are several categories of virtues, among them moral virtues and intellectual virtues. Both are important in the character of the leader. Moral virtues, for example, include characteristics like prudence, fortitude, temperance, and justice, and these may be understood as traits characterized by emotion and desire. On the other hand, intellectual virtues are developed patterns of thinking and include judging the truth of matters and understanding the nature of things. Perhaps a simpler way to articulate the concept of intellectual virtues is to refer to it as practical wisdom. Many philosophers see significant overlap between moral and intellectual virtues. Still, the point is that influential leaders who do not possess virtues will struggle to produce effective outcomes for their followers and organizations. Ultimately, virtues are based upon one's system of values; however, those may be formed. As global leadership expert Margie Warrell once wrote, "We lead by virtue of who we are every time we refuse to play safe. We do it every time we speak up about what's important to us. We do it every time we hold someone accountable. We do it every time we think outside the box. And we do it every time we refuse to let our failures define us, and we challenge what has always been in exchange for what could be" (Warrell, 2013).

Among the several dozen virtues upon which character may be shaped, our ACLRD model identifies integrity as the single most important and relevant virtue. Integrity is defined as strongly adhering to a code of conduct based on a consistent moral code. Simply stated, integrity is complete honesty that fosters trust by others. Integrity transcends corruption and deceit, despite the latter's prevalence. Many philosophers and leadership experts have summarized integrity by expressing it this way: integrity is doing what you say you will do every time, no questions asked. Integrity and trust are essential elements in developing enduring business relationships. The importance of integrity in today's challenging global economy cannot be overstated. If the leader's integrity is consistently confirmed repeatedly, his or her organization will develop customers or clients who hold an unshakable allegiance to its brand. It is easiest to understand by asking yourself a simple question: would you continue to do business with a leader who lies to you? Probably not. Customer loyalty is earned through the consistent demonstration of the virtue of integrity. 
Our research revealed that Ukrainian society values charisma in its leaders. Charismatic leaders are those who display persuasion and eloquent communication to encourage specific behaviors by others. Leaders with charisma inspire eagerness in others to achieve a certain vision or goal and, as a result, can motivate employees to accomplish tasks or even improve the way those tasks are done. Charisma is a force of personality and, in a leader, has its basis in the form of heroism. While charisma is not always as highly valued in other cultural contexts, it ranks high in its value in Ukrainian society. However, charisma may be accompanied with a dark side - often characterized as a selfish, manipulative aspect of one's personality that most would rather not reveal to others - and followers should be aware. When charisma is evident in a leader who does not lead out of the above virtues, the results are often counterproductive. Sometimes, charisma can become manipulative, a way for the leader to get what he wants rather than what is best for the common good.

The Mission Quadrant. Peter Drucker (1973) often asserted that a business is defined by its mission. The mission statement determines behaviors, affects decisions and ensures the commitment of the employees. Establishing the organization's mission is to make prominent its long-term focus. Moreover, an "organization relates its existence and survival to a unique reason and purpose" (Ekpe et al., 2015: 135), which is the essence of the mission statement. It is serves as a strategic planning tool and the framework for evaluating an organization's progress toward its established goals. Purpose and values have a strong positive effect on an organization's performance (Stallworth Williams, 2008). Our data analysis that shaped the Mission Quadrant involved three components: purpose, determination, and confidence. We then added the essential element of vision to frame the role and utility of mission in organizations properly. The Mission Statement (sometimes called a purpose statement) is based on the leader's values, principles, and goals. Therefore, it logically flows from the character dimension of the Leader Model. Without clear self-awareness and an explicit understanding of what one wants to achieve in life and why, it is next to impossible to formulate a distinct, specific, and unambiguous plan for one's life and the life of an organization.

The purpose is the core for formulating a personal and organizational mission statement. It is not what you do, it is why you do it, and that is where purpose and mission meet, as this is the very question the mission statement answers. Your purpose distinguishes you from others. The purpose reveals the unique values you create in the lives of all organizational stakeholders. It gives you a competitive edge, an advantage that you would not have otherwise. Part of the organization's mission is the envisioning of the desired future.

Vision is a picture of where the leader wants the organization to be and how it will look in both the near and distant future to fulfill the mission. As the company grows and changes, however, the vision may well change along with it. Having achieved the milestones established by the vision statement, a leader must articulate the following vision. Therefore, the mission answers the question, why do we exist? And the vision answers the question, what should we become? These answers help fulfill the reason for the organization's existence (those above why). Thus, vision is an integral part of the organization's mission. Leaders and their organizations can expect to encounter much resistance, differences of opinion, and naysayers. In the moments of the strongest doubts and most resistance, a resilient leader must remain focused on the purpose and the goal (mission and vision).

Determination helps a leader to rise above doubts and job-related fatigue. Determination is an important trait that includes initiative, persistence, and drive (Northouse, 2013). Without these qualities, an organization's plans, strategies, and goals will remain little more than ideas but likely will not come to fruition. Motivation is a great igniter, but determination is the fuel that will drive the organization to achieve its desired outcomes.

The Hard Skills Quadrant. Hard skills represent technical skills, such as working with specific computer software or the competencies of an electrician or an accountant. Hard skills can be taught. Typically, a person learns a set of hard skills during his or her career path to leadership. Hard skills often are contrasted with soft skills, which represent interpersonal competencies. Rather than explicitly acquiring soft skills, leaders tend to gain them implicitly through cultivation and even mentoring by some other leader (see the Emotional Intelligence part of the model). Ukrainians seem to favor hard skills in their leaders. Professionalism and skills have been highlighted among the essential qualities of a leader in previous research (Kliuchnikov, 2014). Desiring to grow professionally, most employees want to see their leaders as exemplary professionals in their respective fields, even in highly nuanced ways (Kliuchnikov, 2014). This perception implies that the best leader for a hospital may be the most qualified doctor or that the best school principal is always one of the best teachers. While there may be some merit in this statement (indeed, a leader must understand the field in which he or she is leading), technical knowledge does not count as much in leadership, as do conceptual and interpersonal (soft) skills. 
Therefore, in the ACLRD Leader Model, the hard skills quadrant represents both technical and conceptual skills, emphasizing the conceptual aspects of a leader's responsibilities. Conceptual skills refer to the leader's ability to work with ideas. These skills are "central to creating a vision and strategic plan for an organization" (Northouse, 2013: 46). The higher a leader's position, the more important conceptual skills become. At the same time, technical skills become less important. The third aspect of hard skills in our Leader Model is management. Leadership and management expert Warren Bennis (1989) was well known for his conviction that managers are the people who do things right and leaders are the people who do the right things. Notice some of the subtle differences between the functions of management and leadership:

- The manager administers; the leader innovates.

- The manager focuses on systems and structure; the leader focuses on people.

- The manager relies on control; the leader inspires trust.

- The manager has a short-range view; the leader has a long-range perspective.

- The manager asks how and when; the leader asks what and why.

- The manager has his or her eye always on the financial bottom line; the leader's eye is on future opportunities.

- The manager accepts the status quo; the leader challenges it. (p. 42)

While Bennis's statement is true, it cannot be taken as an absolute. Strategy, values, and the "Big Picture" are critically important. However, leaders need to maintain close contact with their subordinates and to understand the particulars of the daily operations (to avoid setting unreasonable deadlines, failing to properly resource operations, or requiring tasks that are technically impossible for the team). Sutton (2010) properly rephrased Warren Bennis' statement when he asserted, "To do the right thing, a leader needs to understand what it takes to do things right, and to make sure they actually get done" (para. 11).

The Emotional Intelligence Quadrant. Emotional intelligence (often referred to as EQ) represents the collection of emotional and social skills that shape how well we understand ourselves and express ourselves to others. EQ also speaks to how we develop and maintain our relationships with others and how we handle problems. Emotional intelligence falls into the category of "soft skills", the value of which is now recognized across all organizations, especially for leaders.

Perhaps no other aspect of emotional intelligence is more important than self-awareness. Self-awareness is how people consciously know and understand their character, feelings, motives, and desires. Not only do they have an awareness of themself, but they also gain awareness of how their feelings influence their logical decision-making. And, of course, self-awareness also means that the individual acquires a sense of how their words and deeds affect others. A considerable body of research suggests that when leaders are aware of self, they build stronger relationships, communicate more effectively, and make better decisions. The development of emotional intelligence increases occupational performance, leadership, and organizational productivity. Based on data from various sources, emotional intelligence has been conclusively shown to contribute to profitability in any work organization positively. However, the more power a leader possesses, the greater the tendency to overestimate skills and abilities, which is the antithesis of self-awareness. Other research studies have demonstrated that leaders' expert hard skills do not always help them root out false information, question their assumptions, or do their homework. Experience and excellent hard skills sometimes lead to a false sense of confidence about the leader's abilities and, worse, may lead to overconfidence about how they view awareness of themselves. Even though most leaders believe they are self-aware, the majority do not possess well-developed self-awareness.

Empathy is the ability to have an awareness of other people's emotions and to be able to imagine what others may be thinking or feeling. A common expression that reflects empathy is that it is "putting yourself in someone else's shoes". An example of empathy is feeling similar excitement when a friend shares the good news with you. Likewise, empathy is sharing genuine sadness when learning of a friend's troubling news. Displaying empathy involves acknowledging the other person's feelings, good or bad, and then sharing how one shares those feelings. An empathetic person may express appreciation that the other individual was willing to share openly and transparently about their feelings. Empathy toward others means that leaders show interest and offer encouragement and support. Award-winning poet Maya Angelou (Booth \& Hachiya, 2004) once wrote: "I have learned that people will forget what you said, people will forget what you did, but people will never forget how you made them feel" (p. 14).

ACLRD research identified humaneness as another highly valued trait of leaders. The concept of humaneness is often also characterized as benevolence or goodwill. Regardless of which word is used, the terms all suggest 
a disposition to do good regarding others and show compassion and kindness to others' needs. Humaneness has been embraced as a critically important virtue across most human societies, religions, philosophies and cultures. The Chinese philosopher Confucius once said: "The humane man, desiring to be established himself, seeks to establish others; desiring himself to succeed, he helps others to succeed. To judge others by what one knows of oneself is the method of achieving humanity" (Fu, 1994: 41).

Responsibility. As highlighted in the findings, responsibility is the single most crucial aspect of good leadership, as viewed in the Ukrainian culture. That is why our Leader Model encircles the four quadrants. It explicitly suggests that leaders need to be responsible in and for all four quadrants. Exhibiting responsibility implies a proactive stance by a leader. Steven Covey said it best when he wrote that responsibility has two components: ability and response. Therefore, responsibility means demonstrating an ability to respond to any given challenge in any given context. This Leader Model becomes an effective tool only when leaders take a proactive stance in each quadrant by understanding that "the buck stops with them". In other words, no excuses will be made; the leader takes direct responsibility for matters rather than passing the responsibility on to others.

Applying the ACLRD Leader Model in Ukrainian Contexts. The question remains, "should we teach penguins the ways of living in Africa?" In many respects, this may seem to be a rhetorical question, one to which some business leaders may say, of course not. To others, this is a vital question that holds promise for a better future. There is only one correct response to this question that offers the way forward to the possibility of a sustainable, prosperous future: YES, not only should we learn new ways of leading organizations but in this highly complex global economy of which we all are now a part, we also simply cannot ignore learning these new ways if we want to be competitive and usher in the types of changes that Ukrainian society so desperately need! The Leader Model we propose cannot be applied effectively using conventional ways of thinking. Instead, those who oversee businesses, nonprofits, and every other type of organization must transform the way they approach the world as it exists today. Albert Einstein warned that one could not use outdated approaches to solve new and fundamentally different - problems (Jones et al., 2008). Corruption, the lack of innovation, the inability to bring longevity to organizations - these and many other problems cannot be solved with "the way we have always done things here". Applying the ACLRD Leader Model to existing mindsets and operating, currently reflected in Ukraine's high-Power Distance, paternalistic culture with strong nepotism ties that stem from collectivistic mentality, will simply not work. However, the model is based on data collected in Ukraine. Without question, Ukrainians are demanding new ways of leading people. Employees and owners/managers alike realize that to succeed, they need both to exemplify and experience a different type of working relationship, one that is best expressed through the Leader and Follower partnership.

This Leader Model does not promise immediate financial gain; instead, it provides a roadmap to creating lasting and meaningful impact that ultimately will create a cultural context conducive to economic growth at the individual, organizational, and national levels. Implementing the needed changes recommended by this Model likely will not occur without some difficulties. One reason for that is that changing organizations is considered difficult, irrespective of culture or nation. Fostering change in organizations is challenging to begin and even harder to sustain. The potential rewards in long term sustainability make those difficulties worthwhile.

Cultural shifts are challenging endeavors. By their very nature, they are disruptive. Yet, that is precisely the point. Disruption is the path to positive change. To create disruptive change, leaders must think outside of existing cultural paradigms while also working within them. Doing so requires effort, discipline, and resilience. For those reasons, the Leader Model starts with character. Only through deep personal convictions are leaders going to set and maintain a proper course toward creating new business realities and societal norms in Ukraine. By developing a mission, leaders will articulate how they envision the desired future and why it is essential to stand by one's principles. Hard skills allow leaders to become experts in their respective fields; however, conceptual skills will shape leaders' success and the success of their organizations. Leaders must develop the relational solid skills and abilities necessary to work effectively with their workforce. After all, without followers, there are no leaders! An excellent place to start with developing these skills is emotional intelligence, which brings us back to one's character. As leadership researchers Kouzes and Posner (2008) often remind us, leadership is "an affair of the heart" (p. 136). One must care for people and at its core, this is a character trait rather than a mere skill.

The ACLRD Leader Model serves as a change catalyst for Ukrainian organizations. To shed the practices that have long helped hold it back from being a thriving and prospering nation, the time has come for those in charge of Ukrainian organizations to move past being начальники (Ukrainian word for "chief" or "boss") and 
to grow into being true leaders. Ukrainian society deserves nothing less. At the Analytical Center for Leadership Research and Development (ACLRD), we invite you to join a dialogue with us as to what that might look like for your organization. ACLRD provides further research and training in the practical applications of this model for organizations of all types.

Author Contributions: Conceptualization: Michael Linville, Artem Kliuchnikov; data curation: Artem Kliuchnikov; formal analysis: Michael Linville, Artem Kliuchnikov; investigation: Artem Kliuchnikov; methodology: Michael Linville, Artem Kliuchnikov; project administration: Michael Linville; resources: Michael Linville; software: Artem Kliuchnikov; supervision: Michael Linville; validation: Michael Linville, Artem Kliuchnikov; visualization: Michael Linville, Artem Kliuchnikov; writing - original draft: Michael Linville, Artem Kliuchnikov; writing - review \& editing: Michael Linville, Artem Kliuchnikov.

Funding. There is no funding for this research.

\section{References}

1. 50 експертів оцінили роботу президента Порошенка за 12-бальною системою [50 ekspertiv otsinyly robotu prezydenta Poroshenka za 12-bal'noyu systemoyu] (July 20, 2018). Available at: [Link]

2. Aristotle (1981). The politics (Rev. ed., T. A. Sinclair, Trans., T. J. Saunders, Rev and re-presented), page 88. Penguin. Available at: [Link]

3. Aurelius, M., \& Gill, C. (2013). Meditations. Oxford University Press. 221 p. [Google Scholar]

4. Bennis, W. (1989). On becoming a leader. Addison-Wesley. 266 p. Available at: [Link]

5. Bennis, W., \& Nanus, B. (1985). Leaders: The strategies for taking charge. Harper \& Row. 244 p. [Google $\underline{\text { Scholar }}$

6. Booth, D., \& Hachiya, M. (2004). The Arts Go to School. Pembroke Publishers. 160 p. [Google Scholar]

7. Brooks, D. (2012). The social animal: The hidden sources of love, character, and achievement. Random House. 424 p. Available at: [Link]

8. Cheng, B., Chou, L., Wu, T., Huang, M., Farh, J. (2004). Paternalistic leadership and subordinate responses: Establishing a leadership model in Chinese organizations. Asian Journal of Social Psychology, 7(1), 89-117. [Google Scholar] [CrossRef]

9. Covey, S.R. (2004). The 7 habits of highly effective people: Restoring the character ethic (Rev. ed.). Free Press. 372 p. [Google Scholar]

10.Drucker, P. (1973). Management: Tasks, responsibilities, practices, 32-33. Harper. [Google Scholar]

11.Dubnick, M.J. (2003). Accountability and ethics: Reconsidering the relationships. International Journal of Organizational Theory and Behavior, 6(3), 405-441. [Google Scholar] [CrossRef]

12.Ekpe, E.O., Eneh, S.I., \& Inyang, B.J. (2015). Leveraging organizational performance through effective mission statement. International Business Research, 8(9), 135. [Google Scholar] [CrossRef]

13.Ember, C., \& Ember, M. (2014). Cultural anthropology. Pearson Publishing. Available at: [Link]

14.Fairhurst, G.T., \& Grant, D. (2010). The social construction of leadership: A sailing guide. Management Communication Quarterly, 24(2), 171-210. [Google Scholar] [CrossRef]

15.Farh, J.L., Cheng, B.S. (2000). A cultural analysis of paternalistic leadership in Chinese organizations. In Li, J. T., Tsui, A. S., Weldon, E. (Eds.), Management and organizations in the Chinese context (pp. 84-127). Macmillan. [Google Scholar] [CrossRef]

16.Fey, C.F., Adeava, M. \& Vitkovskaia, A. (2001). Developing a model of leadership styles: What works best in Russia? Working Paper \#00-103R1. Stockholm School of Economics in St. Petersburg. Available at: [Link]

17.Fu, Z. (1994). Autocratic tradition and Chinese politics. Cambridge University Press. 401 p. [Google Scholar]

18.Gardberg, N.A. (2006). Reputatie, Reputation, Réputation, Reputazione, Ruf: A cross-cultural qualitative analysis of construct and instrument equivalence. Corporate Reputation Review, 9(1), 39-61. [Google Scholar] [CrossRef]

19.Goodburn, M. (2015, January 24). What is the life expectancy of your company? [Online forum post]. Available at: [Link]

20.Hofstede, G.H. (2001). Culture's consequences: comparing values, behaviors, institutions, and organizations across nations ( $2^{\text {nd }}$ ed.). Sage Publications. 616 p. [Google Scholar]

21.Holt, S., Bjorklund, R., \& Green, V. (2009). Leadership and culture: Examining the relationship between cultural background and leadership perceptions. Journal of Global Business Issues, 3(2), 149-164. [Google $\underline{\text { Scholar] }}$ 
22.House, R.J., Dorfman, P.W., Javidan, M., Hanges, P.J., \& de Luque, M.S. (2014). Strategic leadership across cultures: GLOBE study of CEO leadership behavior and effectiveness in 24 countries. Sage Publications Inc. 464 p. [Google Scholar]

23.Jhangiani, R., \& Tarry, H. (2015). Principles of social psychology. University of Minnesota Libraries Publishing. [Google Scholar]

24.Jones, A., Deshmukh, A., Kumara, S., \& Li, M. (2008). Engineering Complex, Information-Based, Networked Industrial Systems: A Research Roadmap. Journal of Computing and Information Science in Engineering, 8, 011005. [Google Scholar] [CrossRef]

25.Kets de Vries, M.F.R. (2000). A Journey into the "Wild East": Leadership style and organizational practices in Russia. Organizational Dynamics, 28(4), 67-81. [Google Scholar] [CrossRef]

26.Kim, U., Yang, G., \& Huang, G. (2006). Indigenous and cultural psychology: Understanding people in context. Springer. 518 p. [Google Scholar]

27.Kliuchnikov, A. (2014). A cross-cultural study of effective leadership attributes in Ukraine and Russia [Doctoral Dissertation, Regent University, Virginia Beach]. ProQuest Dissertations \& Theses A\&I. [Google Scholar]

28.Kouzes, J., \& Posner, B. (2002). The leadership challenge (3rd Ed.). Jossey-Bass. 496 p. [Google Scholar]

29.Kouzes, J.M. \& Posner, B.Z. (2008). The leadership challenge (4th ed.). Jossey-Bass. Available at: [Link]

30.Lipman-Blumen, J. (2006). The allure of toxic leaders: Why we follow destructive bosses and corrupt politicians - and how we can survive them. Oxford University Press. 303 p. [Google Scholar]

31.Lord, R.G., Brown, D.J., Harvey, J.L., \& Hall, R.J. (2001). Contextual constraints on prototype generation and their multilevel consequences for leadership perceptions. The Leadership Quarterly, 12(3), 311-338. [Google Scholar] [CrossRef]

32.McCarthy, D.J., Puffer, S.M., \& Darda, S.V. (2010). Convergence in entrepreneurial leadership style: Evidence from Russia. California Management Review, 52(4), 48-72. [Google Scholar] [CrossRef]

33.McGregor, D. (1960). The human side of enterprise. McGraw-Hill. Available at: [Link]

34.Miller, T. (1993). The duality of human nature. Politics and the Life Sciences, 12(2), 221-241. [Google Scholar] [CrossRef]

35.Northouse, P.G. (2013). Leadership: Theory and practice ( $6^{\text {th }}$ ed.). Sage Publications. Available at: [Link]

36.Offermann, L.R., \& Coats, M.R. (2018). Implicit theories of leadership: Stability and change over two decades. The Leadership Quarterly, 29(4), 513-522. [Google Scholar] [CrossRef]

37.Our Thinking. (2020). Available at: [Link]

38.Ozolinšs, J.T. (2017). Creating the civil society East and West: Relationality, responsibility and the education of the humane person. Educational Philosophy and Theory, 49(4), 362-378. [Google Scholar] [CrossRef]

39.Sarros, J.C., Cooper, B.K., \& Hartican, A. M. (2006). Leadership and character. Leadership \& Organization Development Journal, 27(8), 682-699. [Google Scholar] [CrossRef]

40.Schwartz, B., \& Sharpe, K. E. (2006). Practical wisdom: Aristotle meets positive psychology. Journal of Happiness Studies, 7, 377-395. [Google Scholar] [CrossRef]

41.Stallworth Williams, L. (2008). The mission statement: A corporate reporting tool with a past, present, and future. Journal of Business Communication, 45(2), 94-119. [Google Scholar] [CrossRef]

42.Sutton, R.I. (2010). True leaders are also managers. Harvard Business Review. Available at: [Link]

43.Tjeltveit, A.C. (2003). Implicit virtues, divergent goods, multiple communities: Explicitly addressing virtues in the behavioral sciences. American Behavioral Scientist, 47(4), 395-414. [Google Scholar] [CrossRef]

44.Ünler, E., \& Kılıç, B. (2019). Paternalistic leadership and employee organizational attitudes: The role of positive/negative affectivity. SAGE Open, 9(3). [Google Scholar] [CrossRef]

45.Warrell, M. (2013). You lead by virtue of who you are. Available at: [Link]

46.Wood, W.J. (1998). Epistemology: Becoming intellectually virtuous. IV Press. 216 p. Available at: [Link]

47.Devjat prychyn chomu prograv Poroshenko i shho robyty dali (n.d.). (2020). Available at: [Link] 